\title{
Resting-State Functional Connectivity Mediating for Phonation by the Thalamus in Parkinson's Disease
}

\author{
Sun Woo Kima, Yeong-Hun Park ${ }^{\mathrm{b}}$ \\ ${ }^{a}$ Department of Speech \& Language Rehabilitation, Suncheon Jeil College, Suncheon, Korea \\ ${ }^{b}$ Department of Biomedical Engineering, Hanyang University, Seoul, Korea
}

Correspondence: Sun Woo Kim, MS

Department of Speech \& Language Rehabilitation, Suncheon Jeil College, 17 Jeildaehak-gil, Suncheon 57995, Korea

Tel: +82-61-740-1311

Fax: +82-61-740-1335

E-mail: swkim@suncheon.ac.kr

Received: March 31, 2020

Revised: April 27, 2020

Accepted: April 27, 2020

This work was supported by the Ministry of Education of the Republic of Korea and the National Research Foundation of Korea (NRF2015S1A5A8017149).

\begin{abstract}
Objectives: Phonation impairment is a frequent symptom in patients with Parkinson's disease (PD). Phonation generally worsens as the disease progresses, causing a progressive loss of communication abilities and increasing isolation from society. Despite our understanding of the sites primarily responsible for phonation in normal subjects (NS), alteration of the functional network in patients with PD still remains unclear. The aim of the present study was to provide evidence of neural systems of phonation, using the resting-state fMRI (rs fMRI) technique, that in comparison to NS, patients with PD exhibited altered functional connectivity associated with the thalamus. Methods: We acquired rs $\mathrm{fMRI}$, and then analyzed the functional interactions from the seed regions of interest (ventral thalamic nuclei). This study included 14 patients with PD and 10 NS. All participants underwent fMRI scanning with a 3.0-Tesla MRI scanner to obtain T2*-weighted single-shot echo planar imaging sequences. Results: The results showed that the patients with PD, in the "ON" medication state, exhibited reductions in the right thalamus and both hemispheres of the cortex in the phonation network compared with controls. Specifically, in the PD group, the right thalamus seeds showed strong contralateral connections with the left cortex. In addition, a positive correlation was found between the left precuneus and the both frontal lobules $(r>.60)$ in the PD group. Conclusion: Using the rs fMRI technique, we provided evidence that the patients with PD exhibited a significantly lower functional connectivity when compared to the NS group in relation to phonation control. Also, our data demonstrated bilateral organization of the rs connectivity in contrast to dominant functional influence of the left hemisphere on correlation organization, and recruitment of the right thalamus within the PD group.
\end{abstract}

Keywords: Parkinson's disease, Resting-state fMRI, Functional connectivity, Thalamus, Phonation 간뇌(diencephalon) 중 가장 큰 구조인 시상(thalamus)은 해부학 적으로 제3뇌실(third ventricle)을 사이에 두고 대뇌피질하의 정중 시상(midsagittal)에 타원형으로 자리잡은 한 쌍의 핵군이다(Bhatnagar, 2002). 시상은 체감각, 청각, 미각, 시각의 감각신경 정보(후 각 제외)를 일차영역(primary areas)으로, 기저핵 및 소뇌에서 출력 된 운동신경 정보를 감각운동영역(sensorimotor regions)으로 전 달하는 '중계(relays)'의 역할이 전통적으로 강조되어왔다. 그러나 시상은 수동적 중계소로의 역할뿐만 아니라 대뇌피질에서 직접 신 경신호를 유입받거나(Haber \& Knutson, 2010; Sherman, 2007) 신 경신호가 시작된 대뇌피질로 신경정보를 재투사하면서(Alexan- der, DeLong, \& Strick, 1986; Parent \& Hazrati, 1995) 대뇌피질과 피질 간의 교통(communication)을 변형 및 조정한다는 사실이 점 차적으로 증명되고 있다(McFarland \& Haber, 2002; Sherman \& Guillery, 1996). 시상에는 많은 핵군이 존재하는데 시상으로 들어 가는 섬유(afferent fibers)의 종류에 따라 일차핵(first order nuclei, 말초에서 받아들여진 신경신호의 유입) 혹은 고차핵(higher order nuclei, 대뇌피질에서 시작된 신경신호가 기저핵 혹은 소뇌 등을 경 유하여 유입)으로 이분되거나(Guillery, 1995), 시상피질섬유(thalamocortical fibers)의 분산 형태에 따라 특수핵(specific nuclei, 특 정 대뇌피질 영역으로 섬유 투사) 혹은 비특수핵(nonspecific nu- 
clei, 광범위한 대뇌피질 영역으로 섬유 투사)으로 구분된다(Lorente de Nó, 1938).

대뇌 피질-피질 간의 교통을 조정하는 시상의 기능은 첫째 동일 기능을 수행하는 연결망(network) 내의 상호작용을 촉진하는 ‘주 변 중심(provincial hub)'의 역할, 둘째 이질적 기능을 수행하는 여 러 연결망 사이의 상호작용을 촉진하는 '연결 중심(connector hub)' 의 역할로 설명된다(Hwang, Bertolero, Liu, \& D'esposito, 2017). 고 전적 관점인 양식 특이 중계(modality-specific relays)에 근거하면 시상은 주변 중심의 역할이 강조되는데 말 산출을 일례로 들면 다 음과 같다. 기저핵(basal ganglia)에서 방출된 신경신호는 시상의 배쪽앞핵(ventral anterior nucleus)을, 소뇌에서 방출된 신경신호 는 배쪽외측핵(ventrolateral nucleus)을 경유하여 전전두엽(prefrontal cortex), 전운동영역(premotor area), 보조운동영역(supplementary motor area, SMA), 일차운동영역(primary motor cortex, $\mathrm{M} 1$ )으로 전달되어 수의적 및 숙련된 움직임을 유발하는데 이 과정 에서 시상은 운동정보의 흐름에 관여한다는 것이다. 그러나 보다 진보한 뇌영상 연구는 의사소통의 주요 매개체인 말은 운동뿐만 아니라 언어 및 인지(예: 의미처리, 기억부호화, 집행기능 등)가 관여 하는 통합적 신경 연결망(Horwitz \& Braun, 2004)에 기반하며 시 상은 개별 연결망 간의 정보를 통합하고 조율하는 중심(hub)으로 기능한다고 주장되고 있다(Fuertinger, Horwitz, \& Simonyan, 2015;

Hwang et al., 2017; Tomasi \& Volkow, 2011).

파킨슨병(Parkinson's disease, $\mathrm{PD}$ )은 신경전달 물질의 불균형으 로 인해 증가한 기저핵의 억제성 신호가 시상의 활동을 감소시켜 결 과적으로 대뇌피질의 기능을 저하시키는 대표적인 운동저하형(hypokinetic type) 장애이다(DeLong, 1990). PD 환자의 말산출을 양전 자방출단층촬영(positron emission tomography, $\mathrm{PET}$ ) 또는 기능자 기공명영상(functional magnetic resonance imaging, fMRI)을 활용 하여 살펴본 선행연구들에 따르면 $\mathrm{PD}$ 환자의 병리적 말 상태는 전 통적으로 강조되어온 말산출 핵심 뇌영역 간의 연결 변화, 정상군에 비해 활성화가 증가한 주변 뇌영역의 작용, 혹은 핵심 말 운동영역 과 함께 작용하는 뇌영역의 변화 등으로 다양하게 설명되고 있다 (Pinto et al., 2011; Rektorova, Barrett, Mikl, Rektor, \& Paus, 2007; Rektorova, Mikl, Barrett, Marecek, Rektor, \& Paus, 2012; Sachin et al., 2008). 관련 뇌영역으로 시상이 주요하게 언급되고 강조되는데 (Henderson, Carpenter, Cartwright, \& Halliday, 2000; Maillet et al., 2012) 그 이유는 조절회로를 통해 기저핵과 소뇌의 정보를 전달하 면서 직접 혹은 간접적으로 대뇌의 수의적 운동에 관여하기 때문이 다. 이 과정에서 배쪽앞핵과 배쪽외측핵을 통해 경유한 신경정보가 연결된 대뇌피질의 말운동 기능을 조율하는 것으로 알려져 있다.
$\mathrm{PD}$ 환자의 $70 \%$ 이상에서 발병 후 말(speech) 또는 음성(voice) 관련 문제를 경험하며(Logemann, Fisher, Boshes, \& Blonsky, 1978; Pinto et al., 2004), 특히 질환의 중증도가 중고도(moderate to severe)인 집단이 경도(mild)인 집단에 비해 말산출 시에 느끼는 불편 함과 어려움이 증가한다는 사실(Hartelius \& Svensson, 1994; Ho, Iansek, Marigliani, Bradshaw, \& Gates, 1999; Kim, Kim, \& Yoon, 2018; Logemann et al., 1978; Sapir et al., 1999)은 발성단계에서 유 발된 의사소통 문제가 $\mathrm{PD}$ 환자의 삶의 질을 지속적으로 저하시키 는 주요 요인이라는 사실을 뒷받침한다.

이에 본 연구는 휴식상태(resting-state, rs) fMRI를 활용하여 발 성에 관여하는 주요 핵으로 알려진 배쪽시상핵과 대뇌피질 간의 기능적 연결성(functional connectivity, $\mathrm{FC}$ )을 정상군과 비교하고 자 한다. 아무런 생각도 하지 않는 짧은 시간(10분 내외) 동안 획득 된 영상이 특정 과제기반 수행 동안 나타나는 뇌의 기능적 연결과 매우 유사하며, 임상적 장애 연구에서 발생할 수 있는 개인차 변수 를 통제하고, 환자의 피로도를 경감시킨다는 장점에 근거하여(Jeong \& Kang, 2016) 발병 후 변화된 뇌기능에 대한 객관적 자료를 rs $\mathrm{fMIR}$ 를 활용해 확인하고자 한다.

\section{연구방법}

\section{연구대상}

본 연구는 신경과 전문의에 의해 특발성(idiopathic) $\mathrm{PD}$ 로 진단 된 환자 14 명(남자:여자 $=8: 6$ )과 정상 통제군 10 명(남자:여자 $=4: 6)$ 을 대상으로 하였다. 연구 참가자는 뇌영상 촬영에 앞서 기본/의학 정보수집과 선별검사의 두 단계를 거쳐 적합한 참가자임이 확인되 었는데 그 절차는 다음과 같다. 첫째, 모든 연구 참가자를 대상으로 혈관질환, 뇌 외상, 기타 신경질환, 금속물 체내 삽입, 폐쇄공포증, 비문해, 청력손실의 여부를, 그리고 환자군을 대상으로 뇌심부자 극술 및 언어치료 경험을 추가 조사하여 위의 항목에 해당되는 자 는 연구에서 제외하였다. 둘째, 인지, 언어, 우울이 뇌기능에 미치는 영향을 통제하기 위하여 한국형 몬트리올인지검사(Korean Version of the Montreal Cognitive Assessment, K-MoCA; Kang, Park, $\mathrm{Yu}, \&$ Lee, 2009), 한국판 보스톤 이름대기 검사(Korean VersionBoston Naming Test, K-BNT; Kim \& Na, 1997), 한국판 웨스턴 실 어증 검사(Paradise-Korean version of Western Aphasia Battery Revised, PK-WAB_R; Kim \& Na, 2012), 한국판 노인우울척도(Korean version of the Geriatric Depression Scale, GDS-K; Cho et al., 1999)를 실시하여 연령과 교육수준에 준하여 정상 규준에 포함된 자로 대상을 제한하였다. 그리고, PD 환자군은 개정판 Hoehn과 
Table 1. Subject characteristics for PD and NC groups

\begin{tabular}{lccc}
\hline Characteristic & $\mathrm{PD}(\mathrm{N}=14)$ & $\mathrm{NC}(\mathrm{N}=10)$ & $p$ \\
\hline Age $(\mathrm{yr})$ & $67.35 \pm 7.30$ & $65.40 \pm 4.19$ & .678 \\
Male sex (\%) & $8(57.1)$ & $4(40)$ & .408 \\
Education (yr) & $14.50 \pm 4.55$ & $13.70 \pm 2.58$ & $.024^{*}$ \\
PK-WAB A0 & $97.14 \pm 1.70$ & $96.58 \pm 2.85$ & .680 \\
K-BNT & $51.64 \pm 4.39$ & $52.50 \pm 6.58$ & .408 \\
K-MOCA & $25.21 \pm 2.48$ & $25.70 \pm 3.05$ & .408 \\
GDS-K & $8.42 \pm 5.69$ & $4.40 \pm 3.94$ & .214 \\
POT (yr) & $10.50 \pm 5.54$ & $\mathrm{~N} / \mathrm{A}$ & - \\
M-H\&Y & $2.35 \pm 0.56$ & $\mathrm{~N} / \mathrm{A}$ & - \\
UPDRS III speech & $1.71 \pm 0.83$ & $\mathrm{~N} / \mathrm{A}$ & - \\
\hline
\end{tabular}

Values are presented as mean $\pm \mathrm{SD}$.

$\mathrm{PD}=$ Parkinson's disease; $\mathrm{NC}=$ normal controls; $\mathrm{yr}=$ year; PK-WAB= Paradise Korean version of Western Aphasia Battery (Kim \& Na, 2012); $A 0=$ Aphasia Quotient; K-BNT = Korean Version of the Boston Naming Test (Kim \& Na, 1997); K-MOCA= Korean Version of the Boston Naming Test (Kang, Park, Yu, \& Lee, 2009); Korean version of the Geriatric Depression Scale (Cho et al., 1999); POT=post onset time; M-H\&Y= modified Hoehn \& Yahr Scale (Goetz et al., 2004); UPDRS=Unified Parkinson's Disease Rating Scale (Goetz et al., 2008); N/A = not applicable. ${ }^{*} p<.05$.

Yahr 척도(modified Hoehn \& Yahr scale, M-H\&Y; Goetz et al., 2004)에 근거하여 사지운동장애 정도를, Unified Parkinson's Disease Rating Scale (UPDRS; Goetz et al., 2008)의 운동증상 항목에 근거하여 말 장애 정도를 추가적으로 확인하였다.

두 집단은 교육년수를 제외하고는 연령, 성별 비율, PK-WAB, K$\mathrm{BNT}, \mathrm{K}-\mathrm{MoCA}, \mathrm{GDS}-\mathrm{K}$ 에서 통계적으로 유의미한 차이가 존재하 지 않았다 $(p>.05)$. 본 연구에 참여한 대상자에 대한 구체적인 정보 는 다음의 Table 1 과 같다.

\section{연구절차}

Rs fMRI획득

의사소통을 목적으로 사용되는 발성은 각성 상태에서 이루어지 며 $\mathrm{PD}$ 환자는 깨어 있는 동안에 항파킨슨 제제의 효과가 종료되지 않도록 지속적으로 약물을 복용한다는 점을 반영하여 $\mathrm{PD}$ 환자의 뇌영상은 약물이 효과적으로 작용하는 'ON' 상태에서 수집되었 다. 대상자는 검사 전 눈을 감은 상태에서 특정 생각을 하지 않고 잠에 들지 않도록 주의를 당부받았으며, 검사 중 발생하는 기계 소 음을 차단하기 위한 목적으로 귀마개가 제공되었다. 뇌영상은 3.0 테슬라(Tesla) MRI 스캐너(Achieva, Philips, Best, Netherlands)의 $\mathrm{T} 2 *$ 강조 단발포 에코평면영상(T2* weighted single-shot echo planar imaging)으로 촬영되었고, 다음의 영상지표에 근거하여 수평 으로 스캔되었다: 화적소 크기(voxel size) $2.8 \times 2.8 \times 3.0 \mathrm{~mm}^{3}$, 절 편 수(slice number) 31 (interleaved), 행렬(matrix) $80 \times 80$, 절편 두 께(slice thickness) $3.0 \mathrm{~mm}$, 간격(gap) $1.0 \mathrm{~mm}$, 반복시간(repetition time) 2,000 ms, 에코 시간(echo time) $30 \mathrm{~ms}$, 숙임 각(flip angle) $90^{\circ}$, 영상영역(field of view) $220 \mathrm{~mm}$. 검사가 끝난 직후에 이루어진 검사 중 수면 여부에 대한 질문에 참가 대상자 중 한 명도 잠이 들지 않았던 것으로 확인되었다.

\section{뇌영상 전처리 과정}

Analysis of Functional Neuroimages (http://afni.nimh.nih.gov/ afni) 프로그램이 전처리 과정에 사용되었다. 뇌영상 획득 시 자기 장이 안정화되는 과정에서 신호 불안정이 반영된 영상을 제외하기 위해 각 대상자로부터 획득된 165장의 시계열(time series) 부피 영 상 중 첫 5장을 분석에서 제외했으며, 나머지 자료는 다음의 과정 을 거쳐 처리되었다. 획득된 $\mathrm{fMRI}$ 시계열 중 큰 스파이크를 절단하 는 디스파이킹(despiking), 단면을 획득하는 시간 차이에 의해 발 생한 신호 차이를 맞추는 시간보정(slice timing correction), 그리고 촬영 도중 움직임(예: 머리)으로 인해 발생한 잡음의 영향을 최소화 하기 위한 단면 간의 재정렬(realignment)을 진행하였다.

재정렬 후에는 각 대상자의 뇌의 크기와 위치를 표준화 형판인 Montreal Neurological institute (MNI) 152에 통합하는 공간 표준 화(spatial normalization) 작업을 시행하였다. 보다 정교한 공간 표 준화를 위해 에코평면 영상의 획득 시 함께 획득된 $\mathrm{T} 1$ 구조 영상을 아핀 전환(affine transformation)으로 상호정합(coregistration) 한 뒤 이를 표준 뇌 형판인 MNI 152에 옮기는 과정을 진행하였다. 추가 적으로 $6 \mathrm{~mm}$ full width at half maximum (FWHM) 가우시안 커 널(Gaussian kernel)을 이용한 공간적 잡음을 제거하기 위해 인접 신호들이 서로 유사하도록 조정하는 공간 평활화(spatial smoothing)를 시행하였다. 더불어 대표적인 가외 변인(nuisance variable) 인 백질 및 뇌실에서 발생하는 주변 소음을 제거하기 위한 목적으 로 가외 변인 제거 회귀 방법(nuisance-removal regression)인 ANATICOR (anatomy-based correlation corrections)를 진행하였다(Jo, Saad, Simmons, Milbury, \& Cox, 2010). 다른 조직들의 신호가 혼 합되는 것을 막기 위해 회귀자(regressor)들은 공간 평활화 전에 계 산되었고, ANATICOR 방법의 회귀자들은 다음과 같았다: (1) 머 리 움직임 보정으로부터 획득한 6개 파라미터, (2) 침식된 백질 마 스크에서 국소적 $(r=15 \mathrm{~mm})$ 으로 평균한 신호, 그리고 (3) 침식된 뇌실 마스크에서 평균한 신호. 또한, 가외 변인 제거 회귀 방법은 검 열(censoring)과 대역 통과 여과(band-pass filtering)가 함께 수행 되었다. 검열은 머리 움직임의 1 차 미분 유클리디안 거리 0.25 를 임 계값으로 하여 해당 fMRI 볼륨의 신호를 주변 fMRI 볼륨 신호로 보정하였다. 대역 통과 여과는 신호 신경활동과 관련된 신호 주파 
수만을 선택하기 위해 0.009-0.08 Hz에 해당하는 저주파수만을 추출하였다.

\section{기능적 연결성 분석}

본 연구는 선행연구(Brown et al., 2009)를 통해 발성에 관여하는 핵심 seed로 증명된 관심영역(region of interest, ROI)을 시상에 지 정 $(x / y / z=16 /-19 / 4$ 및 -10/-18/-3)하였다. 좌우의 seed ROI에서 혈중 산소치의존(blood oxygenation level dependent, BOLD) 신호를 추 출한 뒤 전체 대뇌피질에서 씨앗 영역과 시간적으로 유사한 신호변 화 패턴을 보인 시계열 자료에서 상관계수(correlation coefficient) 를 구하였다. 상관계수 $r$ 로 매핑된 뇌영상은 피셔의 $z$ 변환(Fisher's $r$-to- $z$ transformation)에 근거하여 $z$-값의 뇌 영상으로 변환되었다.

\section{자료의 통계적 처리}

Rs fMRI 통계분석은 연령, 성별, 교육년수를 공변량으로 통제한 후 두 집단 $t$ 검정(two-sample $t$-test)을 실시하였고, AFNI에서 제공 하는 Alphashim 프로그램을 이용하여 다중비교를 보정하였다 $(\mathrm{Pa}<.05$, 최소 클러스터 크기가 307 복셀인 $p<.02$ 의 보정되지 않 은 개별 복셀 임계값). 집단 간 FC 비교에서 통계적으로 유의한 차 이가 확인된 대뇌피질의 집단 내 선형적 관련성 분석은 SPSS 23.0 (IBM-SPSS Inc., Chicago, IL, USA)을 사용하여 연령, 성별, 교육년 수를 공변량으로 통제한 뒤 스피어만의 로(Spearman's rho)의 편 상관(partial correlation) 분석을 실시하였다 $(p<.05)$.

\section{연구결과}

\section{집단 간 시상-대뇌피질 간의 $\mathrm{FC}$ 비교}

정상 통제군과 비교 시, $\mathrm{PD}$ 환자군의 시상-대뇌피질 간 $\mathrm{FC}$ 는 유

Table 2. Resting state functional connectivity of the ventral thalamus and cerebral cortex

\begin{tabular}{|c|c|c|c|c|c|c|c|c|}
\hline \multirow{2}{*}{ Seed } & \multirow{2}{*}{$\begin{array}{l}\text { Com- } \\
\text { parison }\end{array}$} & \multirow{2}{*}{ Brain region } & \multirow{2}{*}{ Side } & \multicolumn{3}{|c|}{ MNI coordinates } & \multirow{2}{*}{$t$-value } & \multirow{2}{*}{ Voxels } \\
\hline & & & & $x$ & $y$ & $z$ & & \\
\hline \multicolumn{9}{|c|}{ Lt. VT $\quad \mathrm{PD}=\mathrm{NC}$} \\
\hline \multirow[t]{6}{*}{ Rt. VT } & $\mathrm{PD}<\mathrm{NC}$ & Superior Frontal Gyrus & $\mathrm{L}$ & -4 & 64 & 30 & 7.342 & 939 \\
\hline & & Middle Frontal Gyrus & $\mathrm{L}$ & -38 & 12 & 60 & 8.259 & 4,632 \\
\hline & & Medial Frontal Gyrus & $\mathrm{R}$ & 8 & -28 & 78 & 5.297 & 403 \\
\hline & & Postcentral Gyrus & $\mathrm{R}$ & 56 & -12 & 52 & 9.230 & 2,872 \\
\hline & & Middle Temporal Gyrus & L & -62 & -14 & -4 & 4.823 & 781 \\
\hline & & Precuneus & $\mathrm{L}$ & -10 & -56 & 40 & 6.151 & 1,935 \\
\hline
\end{tabular}

$\mathrm{Lt}$. = left; Rt. = right; VT= ventral thalamus; PD=Parkinson's disease; NC=normal controls; $\mathrm{MNI}=$ Montreal Neurological Institute.
의하게 저하되었다(Table 2). 정상군에 비해 기능적으로 감소된 영 역을 살펴보면 오른쪽 시상-왼쪽 상전두이랑, 오른쪽 시상-왼쪽 중 전두이랑, 오른쪽 시상-오른쪽 내측전두이랑, 오른쪽 시상-오른쪽 중심뒤이랑, 오른쪽 시상-왼쪽 중측두이랑, 오른쪽 시상-왼쪽 쐐기 앞부분이었다(Figure 1). 왼쪽 시상은 정상 통제군과 $\mathrm{PD}$ 환자군 간 에 통계적으로 유의미한 차이를 보인 대뇌피질 영역이 확인되지 않 았다.

\section{집단 내 대뇌피질 간의 상관관계}

FC 비교에서 유의한 차이를 보인 대뇌피질 영역을 대상으로 집 단 내 상관분석을 실시하였다. 정상 통제군은 오른쪽 시상-오른쪽 중심뒤이랑과 오른쪽 시상-왼쪽 쐐기앞부분 $(r=.857, p=.014)$ 간 에, $\mathrm{PD}$ 환자군은 오른쪽 시상-왼쪽 상전두엽과 오른쪽 시상-오른 쪽 내측전두엽 $(r=.812, p=.002)$, 오른쪽 시상-왼쪽 상전두엽과 오 른쪽 시상-왼쪽 중전두엽 $(r=.756 p=.007)$, 오른쪽 시상-왼쪽 중전 두엽과 오른쪽 시상-오른쪽 내측전두엽 $(r=.674, p=.023)$, 오른쪽

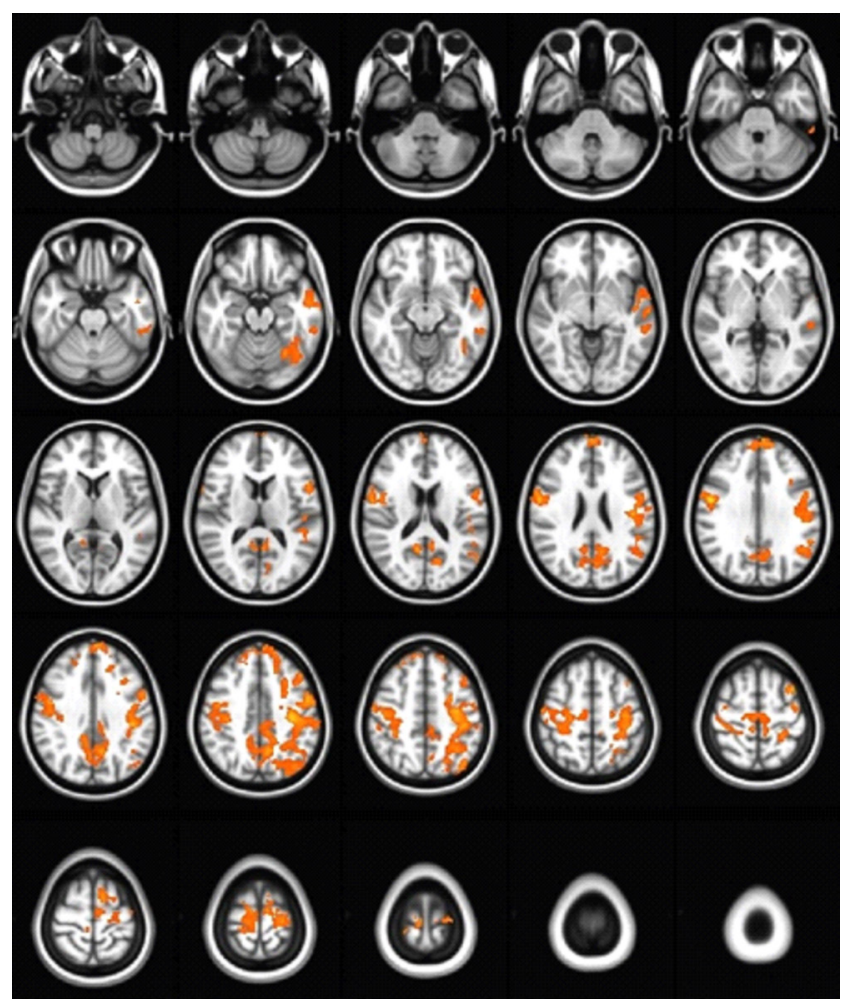

Figure 1. Comparison of functional connectivity of the right thalamus. Patients with Parkinson's disease (PD) showed significantly decreased functional connectivity with the left superior frontal gyrus, left middle frontal gyrus, right medial frontal gyrus, right postcentral gyrus, left precuneus, and left middle temporal gyrus compared with normal controls $(\mathrm{NC})$ (yellow color implies functional connectivity in the $\mathrm{NC}$ group is greater than that in the $\mathrm{PD}$ group). 


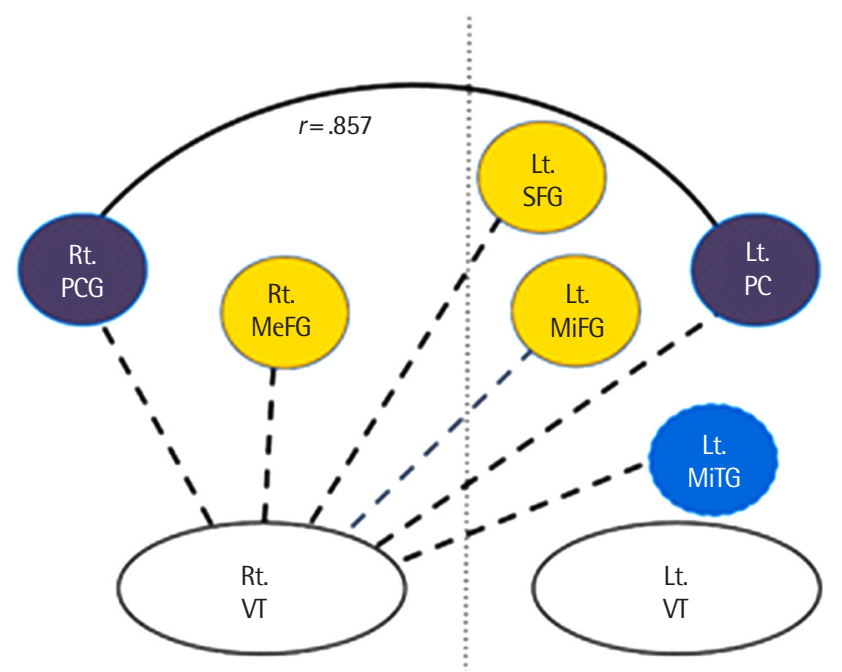

Normal controls

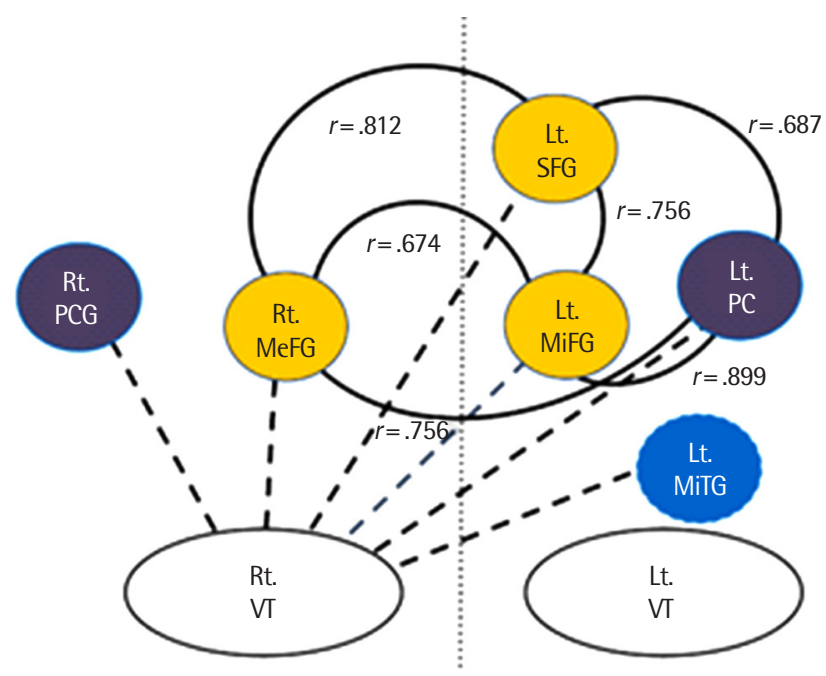

Patients with Parkinson's disease

Figure 2. Distinct thalamus-cerebral cortex connections associated with the phonation of each group.

Rt. = right; Lt. = left; VT= ventral thalamus; PCG= postcentral gyrus; MeFG= medial frontal gyrus; SFG= superior frontal gyrus; MiFG= middle frontal gyrus; PC= precuneus; $\mathrm{MiTG}=$ middle temporal gyrus.

시상-왼쪽상전두엽과 오른쪽시상-왼쪽쐐기앞부분 $(r=.687, p=.019)$, 오른쪽시상-왼쪽중전두엽과 오른쪽시상-왼쪽쐐기앞부분 $(r=.899$, $p<.001)$, 오른쪽 시상-오른쪽 내측전두엽과 오른쪽 시상-왼쪽 쐐 기앞부분 $(r=.756, p=.007)$ 간에 높은 정적 상관관계가 존재하였 다(Figure 2).

\section{논의 및 결론}

특정 자극이 없는 상태에서도 자발적인 신경활동이 존재하며 이 에 따라 국소적으로 증가한 혈류가 발생시킨 저주파수대의 미세한 신호를 추출하여 뇌영역의 기능을 간접적으로 시각화하는 $\mathrm{rs} \mathrm{fMRI}$ 는 방사선 노출의 위험이 없는 비침습적인 검사 방법일 뿐만 아니라 병리상태의 뇌기능을 생체(in vivo)에서 직접 확인 가능하게 한다 는 이점으로 인해 다양한 질환 연구에 널리 활용되고 있다(Lee, Smyser, \& Shimony, 2013; Smith et al., 2013). 이에 본 연구는 PD 환 자를 대상으로 기저핵의 병리가 반영된 배쪽시상핵을 씨앗 영역으 로 지정한 뒤 정상군과의 비교를 통해 발성과 관련된 대뇌피질 영 역과 대뇌피질 영역 간의 $\mathrm{FC}$ 를 분석하였다.

본 연구는 약물이 효과적으로 작용하는 상태임에도 불구하고 $\mathrm{PD}$ 환자군의 $\mathrm{FC}$ 가 통제군에 비해 통계적으로 유의미하게 저하되 어 있음을 확인하였다. 이와 같은 결과는 약물이 ‘ON'인 상태에서 정상군보다 감소한 뇌영역의 활성화를 주장한 선행연구(Festini et al., 2015; Hacker, Perlmutter, Criswell, Ances, \& Snyder, 2012; Kwak et al., 2010)와 그 맥락을 같이하는데 다음과 같은 점을 시사한다.

첫째, $\mathrm{PD}$ 는 기저핵에서 방출된 증가된 억제성 신경전달물질인 감마아미노부티르산( $\gamma$-aminobutyric acid, GABA)이 시상에 유입 되고, 시상에서 방출되는 흥분성 전달물질인 글루타민산(glutamate)이 감소하여 운동을 계획하고 실행하는 전두엽의 활성화가 저하되는 운동감소형 퇴행성 신경질환이다(DeLong, 1990). 이에 따르면 유의하게 저하된 $\mathrm{PD}$ 환자군의 시상-대뇌피질의 기능 활성 화는 신경전달물질의 시상 과억제 및 대뇌피질로 방출되는 흥분성 신경물질의 감소가 반영된 병리기전이기 때문에 항파킨슨제의 복 용은 도파민 경로의 작용을 개선하여 비정상적인 사지운동 증상 을 호전시키는 것으로 알려져 있다. 약물이 효과적으로 작용하는 상태에서 수집된 $\mathrm{FC}$ 를 비교한 본 연구결과는 정상군에 비해 저하 된 PD 환자군의 뇌영역 활성화를 증명하였다. 이러한 결과는 $\mathrm{PD}$ 환자의 마비말장애(dysarthria)는 병이 진전될수록 비도파민 경로 (non-dopamine pathways)의 지배를 받는 뇌영역이 증가하기 때문 이라는 주장에 근거하여 일부가 해석될 수 있다(Agid et al., 1990; Braak et al., 1995; Halliday, Lees, \& Stern, 2011; Kosaka, Tsuchiya, \& Yoshimura, 1988). 이 주장에 따르면 병의 초기단계는 기저핵 이 상이 주된 원인이지만 병이 진전될수록 신체 운동에 비해 말산출 이 상대적으로 비도파민 경로의 영향 하에 놓인다는 것이다. 본 연 구에 참여한 $\mathrm{PD}$ 환자 14 명이 $\mathrm{M}-\mathrm{H} \& \mathrm{Y}$ 의 7점 평정(1.0, 1.5. 2.0, 2.5, $3.0,4.0,5.0$ )에서 2점(균형장애는 없으면서 양측에 증상이 나타난 경우)에서 3 점(약간의 자세 불균형은 있으나 신체적으로 독립적인 
경도에서 중등도의 양측 증상인 경우) 사이의 독립적인 일상생활 이 가능한 수준으로 확인된 반면에 UPDRS 말 관련 5점 평정(0점, 1점, 2점, 3점, 4점)에서는 1점(억양, 말투, 목소리 크기를 잃기는 했 지만 모든 단어가 알아듣기 쉬움)에서 3점(대부분은 아니지만 몇 몇 문장을 알아듣기 어려운 정도로 말을 알아듣기 어려움) 사이의 보다 넓은 중증도 분포를 보여주었다. 위의 사실에 근거해볼 때 제 한적이기는 하지만 도파민제의 복용이 말운동 영역에 미치는 활성 화 효과가 사지운동 관련 영역에 비해 상대적으로 그 영향력이 낮 음을 반영하는 결과라고 볼수 있다.

둘째, $\mathrm{PD}$ 환자군의 왼쪽 시상과 좌우 대뇌피질 간의 $\mathrm{FC}$ 는 정상 군과 차이가 없었지만 오른쪽 시상과 좌우 대뇌피질 간의 $\mathrm{FC}$ 는 유 의하게 저하되었음이 확인되었다. 전통적 관점에서 운동 시상핵 (motor thalamic neurons)은 동측 대뇌피질과 상호고리(reciprocal loops)를 형성하면서 투사(projections)를 형성한다고 알려져 있다 (Jones, 1984; Donoghue \& Parham, 1983). 그러나, 근래에 들어 뇌 영상기법을 활용한 FC 연구들이 증가하면서 일측에만 제한되지 않는 양측 대뇌반구의 동시적 작용이 지속적으로 증명되고 있다. 본 연구에서 일측 시상과 양측 대뇌반구 간의 저하된 $\mathrm{FC}$ 는 앞서 증 명된 기능적 상호 연결이 반영된 결과이며, 더불어 $\mathrm{PD}$ 환자군에서 관찰된 보다 광범위한 왼쪽 대뇌피질 영역의 기능 저하는 말산출과 관련된 후두운동피질(laryngeal motor cortex)이 좌대뇌반구에 위 치하기 때문인 것으로 해석된다(Simonyan, Ostuni, Ludlow, \& Horwitz, 2009). 그 근거를 들자면 타고난 울음과 웃음 등과 관련된 생리적 발성(limbic vocal control pathway)과 달리 말하기 혹은 노 래 등과 같은 수의적 발성(laryngeal motor cortical pathway)은 100 개가 넘는 복잡한 하부 근육들 간의 원활하고 긴밀한 협응을 필요 로 하는데 좌우 대뇌피질의 양측투사를 통해 조율되는 것으로 알 려져 있다(Rouiller, Liang, Babalian, Moret, \& Wiesendanger, 1994). 즉, 본 연구가 FC 분석을 위해 지정한 seed ROI가 선행연구를 통해 수의적 발성과 관련된 주요 영역으로 증명된 곳이며, 연구에 참여 한 모든 대상자가 오른손잡이였기 때문에 $\mathrm{PD}$ 환자군의 좌대뇌반 구 $\mathrm{FC}$ 가 통제군에 비해 유의한 차이를 보였을 가능성이 제기된다.

다음으로 대뇌엽을 기준으로 기능 연결성이 감소된 영역은 전두 엽(왼쪽 상전두엽, 왼쪽 중전두엽, 오른쪽 내측전두엽), 두정엽(오른 쪽 중심뒤이랑, 왼쪽 쐐기앞부분), 측두엽(왼쪽 중측두엽)이었다. $\mathrm{PET}$ 를 활용해 발성에 관여하는 해부학적 영역을 보고한 선행연구 에 따르면 일차감각운동피질(primary sensorimotor cortex), 상측 두이랑(superior temporal gyrus), 보조운동영역이 활성화되고, 체 성감각(somatosensory) 및 청각(auditory) 영역이 감각운동 영역과 통합적으로 상호작용하면서 발성이 집행된다고 주장되었는데(Mur- phy et al., 1997) 이와 같은 근거는 발성이란 말산출과 동일한 영역 을 공유하지만 한편으로는 구분되는 독립적인 영역이 주요하게 관 여함을 시사한다고 할 수 있다. 발성에서 호흡 및 후두의 움직임을 조절하는 신경기제가 분리되어 있는지 아니면 통합되어 있는지를 증명하기 위해 음절 및 호기 산출로 과제를 구분하여 사건 관련 (event-related) fMRI를 시행한 연구에 따르면 음절 과제에서만 내 측전두엽이 활성화된 것을 제외하고는 두 과제 모두에서 전운동영 역을 포함한 감각운동영역과 측두두정엽의 활성화가 확인되었다 (Loucks, Poletto, Simonyan, Reynolds, \& Ludlow, 2007). PD 환자 를 대상으로 한 본 연구에서도 운동처리의 중심인 전두엽뿐만 아니 라 선행연구가 보고한 측두엽과 두정엽을 포함한 유사 영역의 FC 가 확인되어 수의적 발성은 대뇌피질 전반이 관여하는 작용이라는 사실이 지지되었다. 더불어 본 연구는 내측전두엽의 관여를 함께 주장했는데 이는 호기와 달리 음절 및 발성 산출은 화자의 의도가 반영된 결과에 따른 것으로 해석될 수 있다. 반면 본 연구는 전통적 으로 강조되어온 하전두이랑에서 두 집단 간의 차이 있는 결과를 제시하지 못했는데 이는 하전두이랑은 후두 단계를 포함하는 발성 측면보다는 목적을 가진 긴 발화와 관계된 언어적 표현중추로 기능 하기 때문인 것으로 사료된다(Jürgens, 2002).

본 연구와 선행연구의 차이점을 살펴보면 본 연구에 참여한 $\mathrm{PD}$ 환자들은 보다 광범위한 대뇌피질 영역, 즉 전전두엽과 중측두엽을 포함한 기능저하가 관찰되었다. 이는 학습을 통해 습득된 발성 양 식(말을 사용한 의사소통에서 사용되는 발성)이 인지 및 언어 기능 과 복합적으로 작용한다는 측면에서 살펴 볼 필요가 있다(Fujimoto, Hasegawa, \& Watanabe, 2011; Hage, Gavrilov, \& Nieder, 2013). 본 연구에 참가한 환자군은 인지 및 언어 선별검사에서 정상군과 유사한 수행 수준으로 확인됐지만 참여한 $\mathrm{PD}$ 환자군의 인지 및 언 어 능력 저하 가능성을 간과해서는 안될 것이다. $\mathrm{PD}$ 환자를 대상 으로 이루어진 방사선, 생화학, 뇌영상 등에 기반한 다양한 연구들 은 신경변성은 임상 증상이 발현되기 전(preclinical stage)에 진행 되며(Mantri, Morley, \& Siderowf, 2019), 발병 후 변화된 뇌의 FC는 인지능력에 부정적인 영향을 주며(Wolters et al., 2019), 뇌 기능 저 하는 보다 폭넓은 뇌 영역에 영향을 미친다고 보고된 바 있어 $(\mathrm{Wu}$ et al., 2012) 이 주장들에 근거해볼 때 말운동뿐만 아니라 인지 혹 은 언어를 포함하는 기능의 폭넓은 감소가 발생했음에도 불구하고 선별 임상검사를 통해 확인되지 못했을 가능성에 대한 고려가 필 요하다.

또 다른 차이로는 집단 내 대뇌피질의 $\mathrm{FC}$ 비교에서 정상 집단은 두정엽에 위치하는 쐐기앞부분과 뒤중심이랑 간의 $\mathrm{FC}$ 에서 정적 상관관계를 보인 반면에 $\mathrm{PD}$ 환자군은 쐐기앞부분과 전두엽 영역 
간에 정적 상관관계가 관찰되었다. 188 명의 정상 성인을 대상으로 인지과제 및 휴식상태의 fMRI를 비교 분석한 선행연구에 따르면 쐐기앞부분은 인지기능의 효율성에 관여하는 디폴트 모드 연결망 (default mode network, DMN)을 구성하는 하위 해부영역이지만 전체 기능을 통합하는 핵심으로 작용하며, 더불어 구분된 다수의 연결망 간의 상호작용에 광범위하게 관여한다고 알려져 있다(Tomasi \& Volkow, 2011; Utevsky, Smith, \& Huettel, 2014). 이와 같은 맥락에서 살펴보면 본 연구에서 보여준 쐐기앞부분과 전두엽(상전 두이랑, 중전두이랑, 내측전두이랑) 간의 높은 상관관계는 기존의 피질-기저핵-시상-피질 회로(cortico-basal ganglia-thalamo-cortical circuit)에서 연결 중심으로서의 시상의 기능과 더불어 피질단 계에서 전두엽 영역 간의 교통을 조정하는 주변 중심으로 쐐기앞 부분이 기능할 가능성을 시사하고 있어 추후 관련 연구를 통한 확 인 필요성을 제기하였다고 할 수 있다.

본 연구는 $\mathrm{PD}$ 환자의 주 호소인 발병 후 발성 능력 저하를 증명 하기 위해 발성에 관여하는 주요 핵인 배쪽시상핵에 ROI를 지정한 뒤 $\mathrm{FC}$ 분석을 시행하여 변화된 뇌기능을 확인했다는 점에서 그 의 의를 찾을 수 있다. 반면에 본 연구가 지닌 제한점은 다음과 같다. 첫째, 대상자의 현재 발성능력 수준을 확인할 수 있는 자료가 연구 설계 단계에서 계획되고 수집되지 않아 $\mathrm{FC}$ 가 제공하는 정보의 임 상적 의의를 해석하지 못한다는 한계를 갖고 있다. 둘째, 왼쪽 시상 의 경우 환자군과 정상군의 FC 간에 차이가 없는 것으로 확인되었 는데 이를 설명할 근거를 확보하지 못했다는 점이다. 셋째, 적은 대 상자가 참여하여 연구결과의 보편적 적용과 해석에 제한이 있어 향 후 참가자 확대를 통한 추가 연구의 진행이 요구된다.

$\mathrm{PD}$ 환자가 일상생활에서 호소하는 발성의 어려움은 개인 간, 언 어간, 병의 중증도 등에 따라차이가 존재하지만 문장을 사용한 의 사소통에서 모음이 차지하는 비중은 40-50\%이며(Ramus, Nespor, \& Mehler, 1999) 여기에 유성자음까지 포함시킨다면 발성의 중요성 을 강조하는 것은 결코 지나치지 않다고 할 수 있다. 향후 다양한 연 구 설계와 분석에 기반한 $\mathrm{PD}$ 환자의 발성 기전에 대한 객관적 증명 이 선행되어 말 특성 변화에 대한 바람직한 이해가 동반되고, 나아 가 이에 근거한 적용 가능한 다각적 치료접근방법이 개발되고 적용 된다면 병의 진행과 더불어 발생하는 의사소통능력 저하에 대한 불안감을 완화시켜 궁극적으로는 $\mathrm{PD}$ 환자의 삶의 질 향상에 기여 할 것으로 기대된다.

\section{REFERENCES}

Agid, Y., Graybiel, A. M., Ruberg, M., Hirsch, E., Blin, J., Dubois, B., \& Javoy-
Agid, F. (1990). The efficacy of levodopa treatment declines in the course of Parkinson's disease: do nondopaminergic lesions play a role? Advances in neurology, 53, 83-100.

Alexander, G. E., DeLong, M. R., \& Strick, P. L. (1986). Parallel organization of functionally segregated circuits linking basal ganglia and cortex. Annual Review of Neuroscience, 9(1), 357-381.

Bhatnagar, S. C. (2002). Neuroscience for the study of communicative disorders: Lippincott Williams \& Wilkins.

Braak, H., Braak, E., Yilmazer, D., Schultz, C., de Vos, R. A., \& Jansen, E. N. (1995). Nigral and extranigral pathology in Parkinson's disease. Journal of neural transmission. Supplementum, 46, 15-31.

Brown, S., Laird, A. R., Pfordresher, P. Q., Thelen, S. M., Turkeltaub, P., \& Liotti, M. (2009). The somatotopy of speech: phonation and articulation in the human motor cortex. Brain and cognition, 70(1), 31-41.

Cho, M. J., Bae, J. N., Suh, G. H., Hahm, B. J., Kim, J. K., Lee, D. W., \& Kang, M. H. (1999). Validation of geriatric depression scale, Korean version (GDS) in the assessment of DSM-III-R major depression. Journal of Korean Neuropsychiatric Association, 38(1), 48-63.

DeLong, M. R. (1990). Primate models of movement disorders of basal ganglia origin. Trends in neurosciences, 13(7), 281-285.

Donoghue, J. P., \& Parham, C. (1983). Afferent connections of the lateral agranular field of the rat motor cortex. Journal of Comparative Neurology, 217(4), 390-404.

Festini, S. B., Bernard, J. A., Kwak, Y., Peltier, S., Bohnen, N. I., Müller, M. L., Dayalu, P., \& Seidler, R. D. (2015). Altered cerebellar connectivity in Parkinson's patients ON and OFF L-DOPA medication. Frontiers in Human Neuroscience, 9, 214.

Fuertinger, S., Horwitz, B., \& Simonyan, K. (2015). The Functional Connectome of Speech Control. PLoS Biology, 13(7).

Fujimoto, H., Hasegawa, T., \& Watanabe, D. (2011). Neural coding of syntactic structure in learned vocalizations in the songbird. Journal of Neuroscience, 31(27), 10023-10033.

Goetz, C. G., Poewe, W., Rascol, O., Sampaio, C., Stebbins, G. T., Counsell, C., Giladi, N., Holloway, R. G., Moore, C. G., Wenning, G. K., Yahr, M. D., \& Seidl, L. (2004). Movement disorder society task force report on the Hoehn and Yahr staging scale: status and recommendations. Movement Disorders, 19(9), 1020-1028.

Goetz, C. G., Tilley, B. C., Shaftman, S. R., Stebbins, G. T., Fahn, S., MartinezMartin, P., ... LaPelle, N. (2008). Movement Disorder Society-sponsored revision of the Unified Parkinson's Disease Rating Scale (MDS-UPDRS): 
scale presentation and clinimetric testing results. Movement disorders: official journal of the Movement Disorder Society, 23(15), 2129-2170.

Guillery, R. (1995). Anatomical evidence concerning the role of the thalamus in corticocortical communication: a brief review. Journal of anatomy, 187(Pt 3), 583-592.

Haber, S. N., \& Knutson, B. (2010). The reward circuit: linking primate anatomy and human imaging. Neuropsychopharmacology, 35(1), 4-26.

Hacker, C. D., Perlmutter, J. S., Criswell, S. R., Ances, B. M., \& Snyder, A. Z. (2012). Resting state functional connectivity of the striatum in Parkinson's disease. Brain, 135(12), 3699-3711.

Hage, S. R., Gavrilov, N., \& Nieder, A. (2013). Cognitive control of distinct vocalizations in rhesus monkeys. Journal of Cognitive Neuroscience, 25(10), 1692-1701.

Halliday, G., Lees, A., \& Stern, M. (2011). Milestones in Parkinson's diseaseclinical and pathologic features. Movement Disorders, 26(6), 1015-1021.

Hartelius, L., \& Svensson, P. (1994). Speech and swallowing symptoms associated with Parkinson's disease and multiple sclerosis: a survey. Folia phoniatrica et logopaedica, 46(1), 9-17.

Henderson, J. M., Carpenter, K., Cartwright, H., \& Halliday, G. M. (2000). Degeneration of the centré median-parafascicular complex in Parkinson's disease. Annals of Neurology: Official Journal of the American Neurological Association and the Child Neurology Society, 47(3), 345-352.

Ho, A. K., Iansek, R., Marigliani, C., Bradshaw, J. L., \& Gates, S. (1999). Speech impairment in a large sample of patients with Parkinson's disease. Behavioural neurology, 11(3), 131-137.

Horwitz, B., \& Braun, A. R. (2004). Brain network interactions in auditory, visual and linguistic processing. Brain and Language, 89(2), 377-384.

Hwang, K., Bertolero, M. A., Liu, W. B., \& D’esposito, M. (2017). The human thalamus is an integrative hub for functional brain networks. Journal of Neuroscience, 37(23), 5594-5607.

Jeong, H., \& Kang, E. (2016). Resting-state fMRI analysis: techniques and implications. The Korean Journal of Cognitive and Biological Psychology, 28(3), 445-478.

Jo, H. J., Saad, Z. S., Simmons, W. K., Milbury, L. A., \& Cox, R. W. (2010). Mapping sources of correlation in resting state FMRI, with artifact detection and removal. Neuroimage, 52(2), 571-582.

Jones, E. G. (1984). Laminar distribution of cortical efferent cells. In A. Peters \& E. G. Jones (Eds.), Cerebral cortex (pp. 521-552). New York: Plenum Press.

Jürgens, U. (2002). Neural pathways underlying vocal control. Neuroscience
\& Biobehavioral Reviews, 26(2), 235-258

Kang, Y. W., Park, J. S. Y., Yu, K. H., \& Lee, B. C. (2009). A reliability, validity, and normative study of the Korean-Montreal Cognitive Assessment (KMoCA) as an instrument for screening of vascular cognitive impairment (VCI). Korean Journal of Clinical Psychology, 28(2), 549-562.

Kim, H. A., Kim, S. W., \& Yoon, J. H. (2018). Comparison between self-reported and objective measures on speech characteristics in patients with Parkinson's disease. Communication Sciences \& Disorders, 23(1), 228-241.

Kim, H. H., \& Na, D. L. (1997). Korean version-Boston naming test. Seoul: Hakjisa.

Kim, H. H., \& Na, D. L. (2012). Paradise-Korean version-Western aphasia battery-revised. Seoul: Paradise.

Kosaka, K., Tsuchiya, K., \& Yoshimura, M. (1988). Lewy body disease with and without dementia: a clinicopathological study of 35 cases. Clinical Neuropathology, 7(6), 299-305.

Kwak, Y., Peltier, S., Bohnen, N., Müller, M., Dayalu, P., \& Seidler, R. D. (2010). Altered resting state cortico-striatal connectivity in mild to moderate stage Parkinson's disease. Frontiers in Systems Neuroscience, 4, 143.

Lee, M. H., Smyser, C. D., \& Shimony, J. S. (2013). Resting-state fMRI: a review of methods and clinical applications. American Journal of Neuroradiology, 34(10), 1866-1872.

Logemann, J. A., Fisher, H. B., Boshes, B., \& Blonsky, E. R. (1978). Frequency and cooccurrence of vocal tract dysfunctions in the speech of a large sample of Parkinson patients. Journal of Speech and Hearing Disorders, 43(1), 47-57.

Lorente de Nó, R. (1938). Architectonics and structure of the cerebral cortex. In J. F. Fulton (Ed.), Physiology of the nervous system (pp. 291-330). New York: Oxford University Press.

Loucks, T. M., Poletto, C. J., Simonyan, K., Reynolds, C. L., \& Ludlow, C. L. (2007). Human brain activation during phonation and exhalation: common volitional control for two upper airway functions. Neuroimage, 36(1), 131-143.

Maillet, A., Krainik, A., Debû, B., Troprès, I., Lagrange, C., Thobois, S., Pollak, P., \& Pinto, S. (2012). Levodopa effects on hand and speech movements in patients with Parkinson's disease: a FMRI study. PLoS One, 7(10), e46541.

Mantri, S., Morley, J. F., \& Siderowf, A. D. (2019). The importance of preclinical diagnostics in Parkinson disease. Parkinsonism \& related disorders, 64, 20-28.

McFarland, N. R., \& Haber, S. N. (2002). Thalamic relay nuclei of the basal 
ganglia form both reciprocal and nonreciprocal cortical connections, linking multiple frontal cortical areas. Journal of Neuroscience, 22(18), 81178132.

Murphy, K., Corfield, D. R., Guz, A., Fink, G. R., Wise, R. J. S., Harrison, J., \& Adams, L. (1997). Cerebral areas associated with motor control of speech in humans. Journal of Applied Physiology, 83(5), 1438-1447.

Parent, A., \& Hazrati, L. N. (1995). Functional anatomy of the basal ganglia. I. the cortico-basal ganglia-thalamo-cortical loop. Brain Research Reviews, 20(1), 91-127.

Pinto, S., Mancini, L., Jahanshahi, M., Thornton, J. S., Tripoliti, E., Yousry, T. A., \& Limousin, P. (2011). Functional magnetic resonance imaging exploration of combined hand and speech movements in Parkinson's disease. Movement disorders, 26(12), 2212-2219.

Pinto, S., Ozsancak, C., Tripoliti, E., Thobois, S., Limousin-Dowsey, P., \& Auzou, P. (2004). Treatments for dysarthria in Parkinson's disease. The Lancet Neurology, 3(9), 547-556.

Ramus, F., Nespor, M., \& Mehler, J. (1999). Correlates of linguistic rhythm in the speech signal. Cognition, 73(3), 265-292.

Rektorova, I., Barrett, J., Mikl, M., Rektor, I., \& Paus, T. (2007). Functional abnormalities in the primary orofacial sensorimotor cortex during speech in Parkinson's disease. Movement disorders: official journal of the Movement Disorder Society, 22(14), 2043-2051.

Rektorova, I., Mikl, M., Barrett, J., Marecek, R., Rektor, I., \& Paus, T. (2012). Functional neuroanatomy of vocalization in patients with Parkinson's disease. Journal of the neurological sciences, 313(1-2), 7-12.

Rouiller, E. M., Liang, F., Babalian, A., Moret, V., \& Wiesendanger, M. (1994). Cerebellothalamocortical and pallidothalamocortical projections to the primary and supplementary motor cortical areas: a multiple tracing study in macaque monkeys. Journal of comparative neurology, 345(2), 185-213.

Sachin, S., Kumaran, S. S., Singh, S., Goyal, V., Shukla, G., Mahajan, H., \&
Behari, M. (2008). Functional mapping in PD and PSP for sustained phonation and phoneme tasks. Journal of the Neurological Sciences, 273(1-2), 51-56.

Sapir, S., Pawlas, A., Ramig, L., Countryman, S., O’BRIEN, C., Hoehn, M., \& Thompson, L. A. (1999). Speech and voice abnormalities in Parkinson disease: relation to severity of motor impairment, duration of disease, medication, depression, gender and age. NCVS Status and Progress Report, 14, 149-161.

Sherman, S. M. (2007). The thalamus is more than just a relay. Current Opinion in Neurobiology, 17(4), 417-422.

Sherman, S. M., \& Guillery, R. W. (1996). Functional organization of thalamocortical relays. Journal of neurophysiology, 76(3), 1367-1395.

Simonyan, K., Ostuni, J., Ludlow, C. L., \& Horwitz, B. (2009). Functional but not structural networks of the human laryngeal motor cortex show left hemispheric lateralization during syllable but not breathing production. Journal of Neuroscience, 29(47), 14912-14923.

Smith, S. M., Vidaurre, D., Beckmann, C. F., Glasser, M. F., Jenkinson, M., Miller, K. L., ... Van Essen, D. C. (2013). Functional connectomics from resting-state fMRI. Trends in cognitive sciences, 17(12), 666-682.

Tomasi, D., \& Volkow, N. D. (2011). Association between functional connectivity hubs and brain networks. Cerebral Cortex, 21(9), 2003-2013.

Utevsky, A. V., Smith, D. V., \& Huettel, S. A. (2014). Precuneus is a functional core of the default-mode network. Journal of Neuroscience, 34(3), 932-940.

Wolters, A. F., van de Weijer, S. C., Leentjens, A. F., Duits, A. A., Jacobs, H. I., \& Kuijf, M. L. (2019). Resting-state fMRI in Parkinson's disease patients with cognitive impairment: a meta-analysis. Parkinsonism \& related disorders, 62, 16-27.

Wu, T., Wang, J., Wang, C., Hallett, M., Zang, Y., Wu, X., \& Chan, P. (2012). Basal ganglia circuits changes in Parkinson's disease patients. Neuroscience letters, 524(1), 55-59. 


\section{국문초록}

\section{휴식상태 뇌기능자기공명영상을 활용한 파킨슨병 환자의 발성 관련 배쪽시상핵 기능연결성 분석 김선우 1 박영훈2 \\ ${ }^{1}$ 순천제일대학교 언어치료과, ${ }^{2}$ 한양대학교 생체공학과}

배경 및 목적: 본 연구는 파킨슨병(Parkinson's disease, $\mathrm{PD}$ ) 환자의 말산출 연결망을 증명하기 위해 휴식상태 기능자기공명영상을 활 용하여 발성에 관여하는 주요 핵으로 알려진 배쪽시상핵과 대뇌피질 간의 기능적 연결성(functional connectivity, FC)을 살펴보았다. 방법: 약물이 효과적으로 작용하는 상태인 PD 환자 14 명과 정상 성인 10 명을 대상으로 $3.0 \mathrm{Tesla}$ 로 뇌영상을 획득한 뒤 두 집단 간의 $\mathrm{FC}$ 를 비교하였다. 그리고 집단 간 FC 비교에서 통계적으로 유의한 차이가 확인된 대뇌피질에 대해 집단 내에서 선형적 관련성을 확인 하였다. 결과: 통제군에 비해 PD 환자군은 오른쪽 시상과 좌우 대뇌피질 간의 $\mathrm{FC}$ 가 유의하게 저하되었으며, $\mathrm{FC}$ 가 감소된 대뇌피질 영 역을 구체적으로 살펴보면 좌반구의 상전두이랑, 중전두이랑, 중측두이랑, 쐐기앞부분과 우반구의 내측전두이랑, 중심뒤이랑이었다. 두 집단 간에 차이를 보인 피질영역들 간의 상관관계를 집단 내에서 비교한 결과, 정상 집단은 왼쪽 쐐기앞부분-두정엽 영역(오른쪽 중 심뒤이랑)에서 정적 상관관계 $(r=.857)$ 가 존재한 반면에 $\mathrm{PD}$ 환자군은 왼쪽 쐐기앞부분-전두엽 영역(오른쪽 내측전두이랑, 왼쪽 상전두 이랑 및 중전두이랑) $(r>60)$ 간에 정적 상관관계가 확인되었다. 논의 및 결론: 본 연구를 통해 발병 후 PD 환자군의 발성 능력 감소는 오른쪽 배쪽시상핵과 좌우 대뇌피질 간의 기능적 상호작용 감소와 관련되며, 특히 대뇌피질 단계에서 확인된 쐐기앞부분과 전두엽 영 역 간의 높은 상관관계는 발성에서 쐐기앞부분이 대뇌피질 영역을 통합하는 주변 핵심으로서 기능할 가능성을 시사하였다.

핵심어: 파킨슨병, 휴식상태 뇌기능자기공명영상, 시상, 발성

이 논문은 2015년 대한민국 교육부와 한국연구재단의 지원을 받아 수행된 연구임(NRF-2015S1A5A8017149).

\section{참고문헌}

강연욱, 박재설, 유경호, 이병철(2009). 혈관성 인지장애 선별검사로서 Korean-Montreal Cognitive Assessement (K-MoCA)의 신뢰도, 타당도 및 규 준 연구 한국심리학회지: 임상, 28(2), 549-562.

김향희, 나덕렬(1997). 한국판 보스턴 이름대기 검사. 서울: 학지사.

김향희, 나덕렬(2012). 파라다이스 한국판 웨스턴 실어증검사 개정판. 서울: 파라다이스 복지재단.

김현아, 김선우, 윤지혜(2018). 파킨슨병 말특성에 대한 환자 자가평가척도와 평자가 측정치의 비교. Communication Sciences \& Disorders, 23(1), 228-241.

정호진, 강은주(2016). 휴지 상태 fMRI (rs-fMRI) 분석 기법과 해석. 한국심리학회지: 인지 및 생물, 28(3), 445-478.

조맹제. 배제남. 서국희. 함봉진. 김장규. 이동우. 강민희(1999). DSM-III-R 주요우울증에 대한 한국어판 Geriatric Depression Scale (GDS)의 진단적 타당성 연구. 신경정신의학, 38(1), 48-63.

\section{ORCID}

김선우(제1저자, 교신저자, 교수 https://orcid.org/0000-0002-4001-9051); 박영훈(공동저자, 대학원생 https://orcid.org/0000-0002-0941-1637) 